\title{
Early individualized positive end-expiratory pressure guided by electrical impedance tomography in acute respiratory distress syndrome: a randomized controlled clinical trial
}

\author{
Huaiwu He ${ }^{1}$, Yi Chi ${ }^{1}$, Yingying Yang ${ }^{1}$, Siyi Yuan ${ }^{1}$, Yun Long ${ }^{1 *}$ (D), Pengyu Zhao ${ }^{2}$, Inéz Frerichs ${ }^{3}$, Feng Fu ${ }^{4}$,
} Knut Möller ${ }^{5}$ and Zhanqi Zhao ${ }^{4,5^{*}}$

\begin{abstract}
Background: Individualized positive end-expiratory pressure (PEEP) by electrical impedance tomography (EIT) has potential interest in the optimization of ventilation distribution in acute respiratory distress syndrome (ARDS). The aim of the study was to determine whether early individualized titration of PEEP with EIT improved outcomes in patients with ARDS.

Methods: A total of 117 ARDS patients receiving mechanical ventilation were randomly assigned to EIT group ( $n=61$, PEEP adjusted based on ventilation distribution) or control group ( $n=56$, low PEEP/FiO 2 table). The primary outcome was 28-day mortality. Secondary and exploratory outcomes were ventilator-free days, length of ICU stay, incidence of pneumothorax and barotrauma, and difference in Sequential Organ Failure Assessment (SOFA) score at day 1 ( $\triangle \mathrm{D} 1-\mathrm{SOFA})$ and day 2 ( $\triangle \mathrm{D} 2-\mathrm{SOFA})$ compared with baseline.

Measurements and main results: There was no statistical difference in the value of PEEP between the EIT group and control group, but the combination of PEEP and $\mathrm{FiO}_{2}$ was different between groups. In the control group, a significantly positive correlation was found between the PEEP value and the corresponding $\mathrm{FiO}_{2}(r=0.47, p<0.00001)$ since a given matched table was used for PEEP settings. Diverse combinations of PEEP and $\mathrm{FiO}_{2}$ were found in the EIT group $(r=0.05, p=0.68)$. There was no significant difference in mortality rate ( $21 \% \mathrm{vs.} 27 \%$, EIT vs. control, $p=0.63)$, ICU length of stay $(13.0(7.0,25.0)$ vs $10.0(7.0,14.8)$, median (25th-75th percentile); $p=0.17)$, and ventilator-free days at day $28(14.0(2.0,23.0)$ vs $19.0(0.0,24.0), p=0.55)$ between the two groups. The incidence of new barotrauma was zero. Compared with control group, significantly lower $\triangle \mathrm{D} 1$-SOFA and $\triangle \mathrm{D} 2$-SOFA were found in the EIT group
\end{abstract}

\footnotetext{
*Correspondence: iculong_yun@163.com; zhanqi.zhao@hs-furtwangen.de

${ }^{1}$ Department of Critical Care Medicine, State Key Laboratory of Complex

Severe and Rare Diseases, Peking Union Medical College Hospital, Peking

Union Medical College, Chinese Academy of Medical Sciences, Beijing,

China

${ }^{4}$ Department of Biomedical Engineering, Fourth Military Medical University, 169 Changle Xi Rd, Xi'an, China

Full list of author information is available at the end of the article

This study has been partially presented in abstract form in the $21 \mathrm{st}$

International Conference on Biomedical Applications of Electrical

Impedance Tomography (https://zenodo.org/record/4635480\#.YMPMD

DZKipc)
}

(c) The Author(s) 2021. Open Access This article is licensed under a Creative Commons Attribution 4.0 International License, which permits use, sharing, adaptation, distribution and reproduction in any medium or format, as long as you give appropriate credit to the original author(s) and the source, provide a link to the Creative Commons licence, and indicate if changes were made. The images or other third party material in this article are included in the article's Creative Commons licence, unless indicated otherwise in a credit line to the material. If material is not included in the article's Creative Commons licence and your intended use is not permitted by statutory regulation or exceeds the permitted use, you will need to obtain permission directly from the copyright holder. To view a copy of this licence, visit http://creativecommons.org/licenses/by/4.0/. The Creative Commons Public Domain Dedication waiver (http://creativeco mmons.org/publicdomain/zero/1.0/) applies to the data made available in this article, unless otherwise stated in a credit line to the data. 
$(p<0.001)$ in a post hoc comparison. Moreover, the EIT group exhibited a significant decrease of SOFA at day 2 compared with baseline (paired t-test, difference by $-1(-3.5,0), p=0.001)$. However, the control group did show a similar decrease (difference by $1(-2,2), p=0.131$ ).

Conclusion: Our study showed a $6 \%$ absolute decrease in mortality in the EIT group: a statistically non-significant, but clinically non-negligible result. This result along with the showed improvement in organ function might justify further reserach to validate the beneficial effect of individualized EIT-guided PEEP setting on clinical outcomes of patients with ARDS.

Trial registration: ClinicalTrials, NCT02361398. Registered 11 February 2015—prospectively registered, https://clinicaltr ials.gov/show/NCT02361398.

Keywords: Electrical impedance tomography, PEEP titration, ARDS, Organ function

\section{Introduction}

Positive end-expiratory pressure (PEEP) is often used in acute respiratory distress syndrome (ARDS) with the aim to open collapsed lung regions and keep the lung open. However, inappropriate setting of PEEP may induce further injury to the lung tissue. It remains challenging for the physicians to balance the regional recruitment and overdistension during the PEEP setting. PEEP could be adjusted based on and/or respiratory compliance; however, these global parameters do not accurately reflect the regional lung physiologic responses induced by PEEP [1]. Individualized PEEP setting based on regional respiratory features is gaining great attention.

Electrical impedance tomography (EIT) is a functional imaging tool that can quantify ventilation homogeneity $[2,3]$, as well as regional alveolar recruitment and overdistension at the bedside [4]. Hence, EIT could provide deep insights into regional ventilation and lung mechanics allowing an individualized PEEP for ARDS patients under mechanical ventilation. More and more clinical studies have validated the use of EIT for guiding the PEEP setting in various clinical conditions such as ARDS, acute hypoxemia, general anesthesia, and postoperative cardiac surgery patients at the bedside [2, 5-13]. Using the ARDS network, low $\mathrm{PEEP} / \mathrm{FiO}_{2}$ table to set PEEP is easy and popular in the current clinical practice [14]. Since ARDS patients have a highly variable lung recruitability, an individualized PEEP would be desirable. However, to our knowledge, no randomized controlled trial has been conducted to compare the two strategies of setting PEEP using EIT and the lower PEEP/FiO ${ }_{2}$ table in ARDS patients in ICU. Whether an individualized PEEP setting with EIT could improve patient outcomes remains uncertain and needs to be evaluated.

The aim of this randomized controlled study was to explore whether PEEP setting guided by EIT could improve outcomes compared to $\mathrm{PEEP} / \mathrm{FiO}_{2}$ table from the ARDS network in ARDS patients.

\section{Materials and methods}

This is a single-center, prospective, open-label, randomized controlled trial (ClinicalTrials.gov, NCT02361398). The study was approved by the Institutional Research and Ethics Committee of the Peking Union Medical College Hospital. Informed consent was obtained from all patients or next of kin before data were included into the study.

From November 2018 to September 2020, ICU patients with ARDS were screened for eligibility. The diagnosis of ARDS was based on the Berlin definition [15]. We have included patients with a $\mathrm{BMI}<40$ suffering from ARDS with $\mathrm{PaO}_{2} / \mathrm{FiO}_{2}<300 \mathrm{mmHg}$ (diagnosed by a senior grade intensivist according to the Berlin definition) who were sedated and mechanically ventilated with an expected duration of controlled mechanical ventilation of more than $24 \mathrm{~h}$ and ability to tolerate PEEP titration (up to 21 or $15 \mathrm{cmH}_{2} \mathrm{O}$ ). Patients aged less than 18 years and more than 85 years, pregnant women, and patients at end-stage medical condition were excluded from the study. Contraindications to the use of EIT (automatic implantable cardioverter-defibrillator, chest wounds limiting electrode belt placement, and implantable pumps) were considered.

Moreover, the COVID-19 patients were not included in the present study.

\section{Randomization}

Eligible patients admitted to ICU were enrolled within $24 \mathrm{~h}$ and randomly assigned in a 1:1 ratio to the EIT or the control group (PEEP setting by low $\mathrm{PEEP} / \mathrm{FiO}_{2}$ table). Randomization was achieved with a computer-generated random block design, which was drawn up by an independent operator before the beginning of the study. Treatment allocation was concealed using sequentially numbered, opaque, sealed envelopes. All nurses and other research personnel were blinded to the randomization schedule and block size. 


\section{Intervention}

Patients assigned to the control group continued to receive the low-PEEP strategy using the $\mathrm{PEEP} / \mathrm{FiO}_{2}$ table of the ARDS network protocol [14]. In the EIT group, PEEP titration by EIT was performed at the enrollment. The optimal PEEP determined by EIT was applied for $24 \mathrm{~h}$. Afterward, PEEP was set by the attending physician based on the low $\mathrm{PEEP} / \mathrm{FiO}_{2}$ table. EIT measurements were taken with PulmoVista 500 (Dräger Medical, Lübeck, Germany). A silicone EIT belt with 16 surface electrodes was placed around the patient's thorax at the fourth intercostal space level. EIT data were recorded throughout the PEEP titration in the supine position. During this period, all patients were fully sedated using continuous infusion of midazolam, propofol, fentanyl/ remifentanil/sufentanil, and/or atracurium to prevent any spontaneous breathing.

The procedure of the EIT-based PEEP titration was as follows: 1. All patients were under pressure control mode (driving pressure $12-15 \mathrm{cmH}_{2} \mathrm{O}$ with a tidal volume of $6 \mathrm{ml} / \mathrm{kg}$ predicted body weight, respiration rate 12-15 bpm). 2. PEEP was increased to $21 \mathrm{cmH}_{2} \mathrm{O}$ or $15 \mathrm{cmH}_{2} \mathrm{O}$ for $5 \mathrm{~min}$ from baseline. PEEP was increased to $21 \mathrm{cmH}_{2} \mathrm{O}$, if the baseline PEEP was higher than $10 \mathrm{cmH}_{2} \mathrm{O}$ and the patient tolerated the increase, as assessed by the physician (e.g., impaired circulation). Otherwise, PEEP of $15 \mathrm{cmH}_{2} \mathrm{O}$ was used. 3. PEEP was stepwise decreased from 21 (or 15) $\mathrm{cmH}_{2} \mathrm{O}$ to $0 \mathrm{cmH}_{2} \mathrm{O}$ in steps of $3 \mathrm{cmH}_{2} \mathrm{O}$ every $2 \mathrm{~min}$, and $\mathrm{FiO}_{2}$ was increased to 1 to maintain oxygenation. If $\mathrm{SpO}_{2}$ fell below $88 \%$ during the PEEP decrease, the decrease of PEEP was stopped. 4. Optimal PEEP selection: Two EIT-based parameters were calculated. Regional collapse and overdistension percentages were estimated based on the decrease of regional compliance curve calculated during the decremental PEEP trial, toward either lower or higher PEEP levels [16]. The PEEP level selected for the patients in the EIT group was the intercept point of cumulated collapse and overdistension percentage curves, providing the best compromise between collapsed and overdistended lung. If the intercept point occurred between two PEEP steps, the selected PEEP corresponded to the PEEP step toward the lowest global inhomogeneity index [3]. An example individualized PEEP titration by EIT in one patient is shown in Fig. 1. No recruitment maneuver was performed before the PEEP trial. The PEEP value selected according to low-PEEP strategy of the PEEP-FiO 2 table was noted for individuals in the EIT group, only for comparison purpose.

\section{Other respiratory and circulatory therapy}

Apart from the PEEP selection scheme at day 1, other aspects of care such as small tidal volume ventilation and adjuvant therapies of ARDS were the same for both

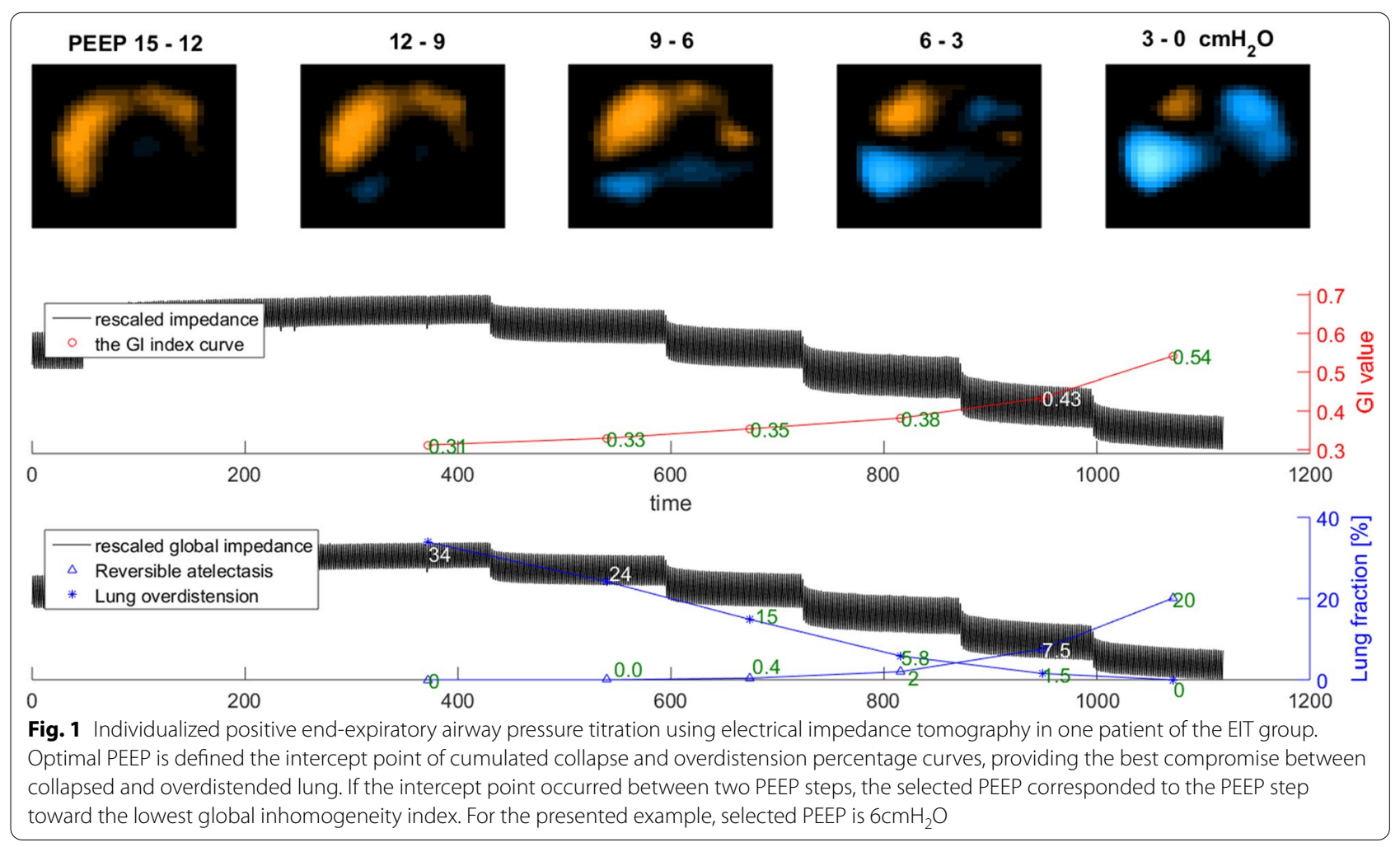


groups based on local ARDS therapy regulation in our department.

All the patients received local hemodynamic support regimens for critically ill patients. The early goals of hemodynamic support for the tissue hypoperfusion were the following: central venous pressure of $8-12 \mathrm{mmHg}$; mean arterial pressure above $65 \mathrm{mmHg}$; urine output above $0.5 \mathrm{ml} / \mathrm{kg}$ of body weight (except in the patients with acute renal failure); and central venous $\mathrm{O}_{2}$ saturation $\left(\mathrm{ScvO}_{2}\right)$ of $70 \%$ or more with the difference between central venous and arterial $\mathrm{PCO}_{2}\left(\mathrm{Pv}-\mathrm{aCO}{ }_{2}\right)$ of $6 \mathrm{mmHg}$ or less. A negative fluid balance management regimen was used after the correction of shock and/or tissue perfusion.

\section{Data collection}

Patients' data were collected on an electronic medical platform. The primary endpoint was all-cause mortality within 28 days after randomization. The secondary endpoints included the number of ventilator-free days at day 28 (if a patient died during the 28-day period after enrollment, the number of ventilator-free days was zero), ICU length of stay, new onset barotrauma (pneumothorax, pneumomediastinum, pneumoperitoneum, or subcutaneous emphysema) during mechanical ventilation. The exploratory endpoints were oxygenation and respiratory mechanics, difference in SOFA score at day 1 [17] after randomization minus baseline SOFA score at enrollment $(\triangle \mathrm{D} 1$-SOFA), as well as the analogous SOFA score difference at day $2(\triangle \mathrm{D} 2$-SOFA).

\section{Statistical analysis}

The sample size was determined to obtain $80 \%$ power with an $\boldsymbol{a}$ level of 0.05 to detect a 25-point difference in 28 -day mortality between the two groups ( $40 \%$ in the control group vs $15 \%$ in the experimental group) and a sample of 57 in each group. In total, 126 patients were enrolled with the aim to manage the dropouts in this study.

Normally distributed results were presented as mean \pm SD, whereas non-normally distributed results were presented as median (25th-75th percentile). Paired data at different time points were compared with the paired sample $\mathrm{T}$ test or the Wilcoxon signed rank test. Mann-Whitney test was used to compare groups on continuous variables, and Chi-square and Fisher's exact tests were used to compare categorical variables. Comparisons of two continuous variables were made using Spearman's correlation. Trend comparisons of the related parameters on different days were performed using a general linear model repeated measures, or so-called repeated measure ANOVA (RM-ANOVA) [18]. This RM-ANOVA model is an extension of the classical ANOVA, which allows handling both fixed effect (different days) and random effect (patient). Bonferroni correction was used to adjust the $\mathrm{p}$ value for multiple comparisons. The statistical analysis was performed by using the software package SPSS 24.0 (SPSS Inc., Chicago, IL) and MedCalc 11.4.3.0 Software (Mariakerke, Belgium). A p value smaller than 0.05 was considered statistically significant.

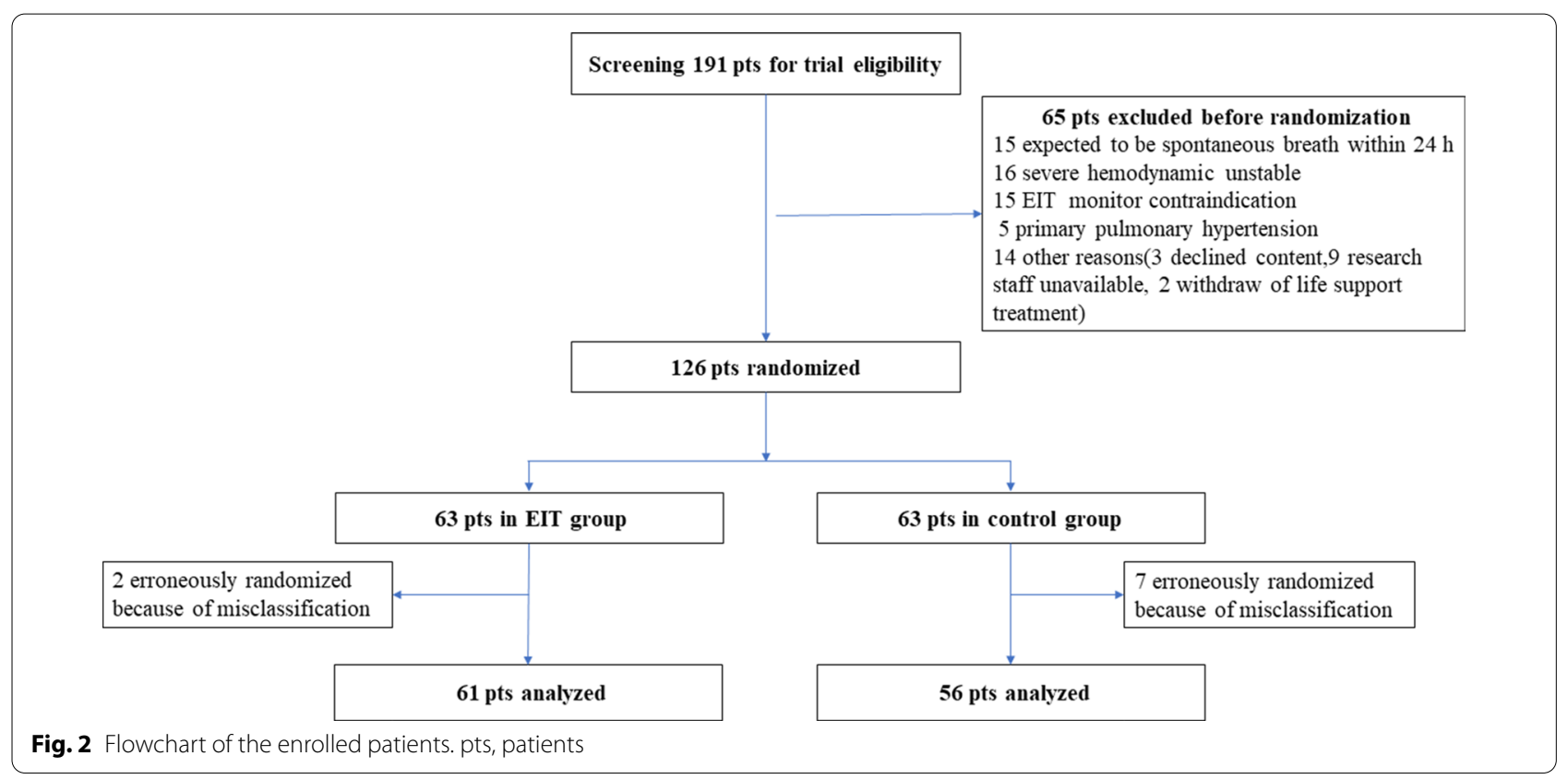




\section{Results}

A total of 191 ARDS patients were screened and 126 were enrolled: 63 patients in the EIT group and 63 in the control group. Two patients in the EIT group and 7 patients in the control group were erroneously randomized because of misclassification of ARDS (Fig. 2). Thus, 117 subjects (61 EIT group and 56 control group) were included in the primary analysis. No patient was extubated, and 12 patients (four in EIT group and eight in control group) had $\mathrm{PaO}_{2} / \mathrm{FiO}_{2}>300$ on the first study day following enrollment.

\section{Patient characteristics}

No significant difference was found in patient characteristics between the two study groups at the baseline (Table 1). Out of 117 patients, 106 received norepinephrine to keep mean arterial pressure (MAP) at the baseline level.

\section{Respiratory and arterial blood gas parameters at baseline} and on days $0,1,2$, and 3

Evolutions of related parameters in both the EIT and the control groups at days $0,1,2$, and 3 are shown in Table 2 . There was no difference in the respiratory parameters and arterial blood gas measurements between the groups. Significant and continuous decreases of lactate, SOFA score and APACHE II score, and an increase of $\mathrm{pH}$ and $\mathrm{PaO}_{2} / \mathrm{FiO}_{2}$ were found in both groups.

\section{PEEP selected by EIT and PEEP/FiO 2 table}

There was no statistical difference in the value of PEEP between the EIT group and control group, but the combination of PEEP and $\mathrm{FiO}_{2}$ was different between groups. In the control group, a significantly positive correlation was found between the PEEP value and the corresponding $\mathrm{FiO}_{2}(r=0.471, p<0.00001)$ in the control group since a given matched table was used for $\mathrm{PEEP} / \mathrm{FiO}_{2}$ settings. In the EIT group, divergent individual combinations of PEEP and $\mathrm{FiO}_{2}$ ranges were found. No correlation was found between the individual PEEP value of EIT titration $\left(\mathrm{PEEP}_{\text {eit }}\right)$ and the corresponding $\mathrm{FiO}_{2}(r=0.053$, $p=0.684$ ) in the EIT group.

In the EIT group, 41/61 patients exhibited an absolute difference value between the PEEP ${ }_{\text {eit }}$ method and $\mathrm{PEEP}_{\text {lower table }}$ method $\geq 2 \mathrm{cmH}_{2} \mathrm{O}$. Distribution of the difference values and agreement of Bland-Altman plot between PEEP ${ }_{\text {eit }}$ and PEEP $P_{\text {lower table }}$ methods are shown in Fig. 3.

Table 1 Baseline clinical characteristics and demographics of patients

\begin{tabular}{|c|c|c|c|}
\hline Variables & EIT group $(n=61)$ & Control group $(n=56)$ & $p$ values \\
\hline Age (years) & $61.0(44.0,68.0)$ & $66.5(50.0,73.0)$ & 0.074 \\
\hline Female Sex & $19 / 61$ & $21 / 56$ & 0.597 \\
\hline Body mass index $\left(\mathrm{kg} / \mathrm{m}^{2}\right)$ & $26.0(22.9,29.1)$ & $26.0(22.9,28.6)$ & 0.933 \\
\hline APACHE II score & $19.0(15.0,25.0)$ & $18.0(15.0,21.2)$ & 0.568 \\
\hline \multicolumn{4}{|l|}{ Reason for ARDS } \\
\hline Pneumonia & $28 / 61$ & $24 / 56$ & 0.884 \\
\hline Extrapulmonary sepsis & 10/61 & $15 / 56$ & 0.252 \\
\hline Severe acute pancreatitis & $0 / 61$ & $1 / 56$ & 0.972 \\
\hline Post-cardiac operation & $14 / 61$ & $8 / 56$ & 0.231 \\
\hline Others & $9 / 61$ & $8 / 56$ & 0.848 \\
\hline Mild ARDS & 18/61 & $23 / 56$ & 0.292 \\
\hline Moderate ARDS & $28 / 61$ & $25 / 56$ & 0.960 \\
\hline Severe ARDS & $15 / 61$ & $8 / 56$ & 0.161 \\
\hline \multicolumn{4}{|l|}{ Other parameters } \\
\hline Heart rate & $98.0(86.0,113.0)$ & $103.0(88.2,120.8)$ & 0.287 \\
\hline Mean arterial pressure & $82.0(73.0,94.0)$ & $87.5(75.8,99.2)$ & 0.242 \\
\hline Received NE ( $n, \%)$ & $53 / 61(86.9 \%)$ & $53 / 56(94.6 \%)$ & 0.151 \\
\hline NE dose (ug/kg/min) & $0.1(0.0,0.3)$ & $0.1(0.1,0.2)$ & 0.715 \\
\hline $\mathrm{ScvO}_{2}(\%)$ & $73.7(71.0,81.7)$ & $76.2(68.7,81.6)$ & 0.953 \\
\hline $\mathrm{Pv}-\mathrm{a} \mathrm{CO}_{2}(\mathrm{mmHg})$ & $4.6(2.6,6.6)$ & $4.3(2.4,7.0)$ & 0.923 \\
\hline Arterial lactate $(\mathrm{mmol} / \mathrm{L})$ & $2.2(1.4,4.7)$ & $2.0(1.4,4.0)$ & 0.550 \\
\hline White blood cell $\left(10 \wedge^{9} / L\right)$ & $9.8(8.6,11.3)$ & $10.3(8.8,12.8)$ & 0.287 \\
\hline
\end{tabular}

ARDS, acute respiratory distress syndrome; $\mathrm{NE}$, norepinephrine; $\mathrm{ScvO}_{2}$, central venous oxygen saturation; $\mathrm{Pv}$-a $\mathrm{CO}_{2}$, venous-to-arterial carbon dioxide difference; APACHE II, Acute Physiology and Chronic Health Evaluation 
Table 2 Difference in respiratory and hemodynamic variables between groups

\begin{tabular}{|c|c|c|c|c|c|}
\hline Parameters & Day 0 & Day 1 & Day 2 & Day 3 & Trend $p$ value \\
\hline \multicolumn{6}{|c|}{$\mathrm{VT}(\mathrm{ml})$ of PC mode } \\
\hline ElT group & $414(383,460)$ & $450(390,520) *$ & $430(373,490)$ & $429(364,497)$ & 0.306 \\
\hline Control group & $407(362,463)$ & $410(370,445)$ & $411(370,481)$ & $426(345,485)$ & 0.153 \\
\hline \multicolumn{6}{|c|}{ Driving pressure $\left(\mathrm{cmH}_{2} \mathrm{O}\right)$} \\
\hline EIT group & $14(11,15)$ & $13(11,15)$ & $13(11,15)$ & $13(11,15)$ & 0.631 \\
\hline Control group & $13(11,15)$ & $13(12,14)$ & $12(11.0,15)$ & $13(10,15)$ & 0.772 \\
\hline \multicolumn{6}{|l|}{ Pmean $\left(\mathrm{cmH}_{2} \mathrm{O}\right)$} \\
\hline ElT group & $10(9,12)$ & $12(10,14)$ & $12(10,14)$ & $12(10,14)$ & 0.065 \\
\hline Control group & $10(9,12)$ & $11(10,13)$ & $12(9,13)$ & $11(10,13)$ & 0.445 \\
\hline \multicolumn{6}{|l|}{$\mathrm{RR}(\mathrm{bpm})$} \\
\hline EIT group & $15(15,15)$ & $15(14,18)$ & $16(15,20)$ & $18(14,22)$ & $<0.0001$ \\
\hline Control group & $15(15,16)$ & $16(15,18)$ & $15(15,18)$ & $17(14,20)$ & $<0.0001$ \\
\hline \multicolumn{6}{|c|}{ Respiratory compliance $\left(\mathrm{ml} / \mathrm{cmH}_{2} \mathrm{O}\right)$} \\
\hline ElT group & $32(27,41)$ & $33(25,43)$ & $31(25,38)$ & $33(25,43)$ & 0.239 \\
\hline Control group & $30(24,37)$ & $30(24,37)$ & $30(24,40)$ & $33(24,43)$ & 0.150 \\
\hline \multicolumn{6}{|l|}{$\operatorname{PEEP}\left(\mathrm{cmH}_{2} \mathrm{O}\right)$} \\
\hline EIT group & $8(6,9)$ & $8(6,9)$ & $8(6,9)$ & $8(6,9)$ & 0.287 \\
\hline $\begin{array}{l}\text { Control group } \\
\mathrm{pH}\end{array}$ & $8(5,10)$ & $8(6,9)$ & $8(6,9)$ & $7(6,9)$ & 0.249 \\
\hline EIT group & $7.4(7.3,7.4)$ & $7.4(7.4,7.5)$ & $7.4(7.4,7.5)$ & $7.4(7.4,7.5)$ & $<0.0001$ \\
\hline Control group & $7.4(7.3,7.4)$ & $7.4(7.4,7.5)$ & $7.5(7.4,7.5)$ & $7.5(7.4,7.5)$ & $<0.0001$ \\
\hline \multicolumn{6}{|l|}{$\mathrm{PaCO}_{2}(\mathrm{mmHg})$} \\
\hline ElT group & $39(36,46)$ & $39(38,43)$ & $42(39,46)$ & $41(38,44)$ & 0.239 \\
\hline Control group & $40(35,43)$ & $41(39,44)$ & $39(37,43)$ & $40(38,43)$ & 0.817 \\
\hline \multicolumn{6}{|l|}{$\mathrm{PaO}_{2}(\mathrm{mmHg})$} \\
\hline EIT group & $82(74,96)$ & $92(76,104)$ & $91(79,110)$ & $96(79,118)$ & 0.183 \\
\hline Control group & $88(70,122)$ & $93(79,111)$ & $96(74,114)$ & $95(78,116)$ & 0.984 \\
\hline \multicolumn{6}{|c|}{$\mathrm{PaO}_{2} / \mathrm{FiO}_{2}(\mathrm{mmHg})$} \\
\hline ElT group & $165(106,213)$ & $187(144,242)$ & $214(165,283)$ & $220(170,295)$ & $<0.0001$ \\
\hline Control group & $176(139,222)$ & $212(170,269)$ & $232(155,316)$ & $231(180,295)$ & 0.001 \\
\hline \multicolumn{6}{|c|}{ Lactate (mmol/L) } \\
\hline EIT group & $2.2(1.4,4.7)$ & $1.9(1.2,2.9)$ & $1.2(1.0,2.0)$ & $1.3(0.9,1.6)$ & $<0.0001$ \\
\hline Control group & $2.0(1.4,4.0)$ & $2.0(1.2,2.8)$ & $1.6(1.1,2.1)$ & $1.4(1.1,1.8)$ & $<0.0001$ \\
\hline \multicolumn{6}{|l|}{ APACHE ॥ } \\
\hline EIT group & $19(14,25)$ & $18(12,24)$ & $15(12,21)$ & $16(12,19)$ & $<0.0001$ \\
\hline Control group & $17(14,20)$ & $18(16,21)$ & $16(13,21)$ & $15(13,20)$ & $<0.0001$ \\
\hline \multicolumn{6}{|l|}{ SOFA } \\
\hline EIT group & $13(11,14)$ & $12(10,14)$ & $11(9,13)$ & $11(9,13)$ & $<0.0001$ \\
\hline Control group & $12(9,13)$ & $12(11,14)$ & $12(10,14)$ & $12(10,14)$ & 0.022 \\
\hline
\end{tabular}

*EIT group versus control group, $p<0.05$. VT, tidal volume; $\mathrm{PC}$, pressure control mode; Pmean, mean airway pressure; RR, respiratory rate; PEEP, positive end-expiratory pressure; APACHE II, Acute Physiology and Chronic Health Evaluation; SOFA, Sequential Organ Failure Assessment

\section{Outcome and adjuvant therapies between groups}

The outcomes are summarized in Table 3. On day 28 after randomization, the death from any causes had occurred in 13 of 61 patients (21\%) in the EIT group and 15 of 56 patients $(27 \%)$ in the control group $(p=0.634)$ (Table 3 and Fig. 4). There were no significant differences in ventilator-free day at day 28 , rate of successful extubations, length of ICU day, and adjuvant therapies of ARDS between the groups (Table 3). The incidence of new barotrauma was zero.

Significantly lower $\triangle \mathrm{D} 1$-SOFA and $\triangle \mathrm{D} 2$-SOFA were found in the EIT group (Table 3). Moreover, the EIT group exhibited a significant decrease of SOFA at day 2 compared with baseline (paired t-test, difference by 

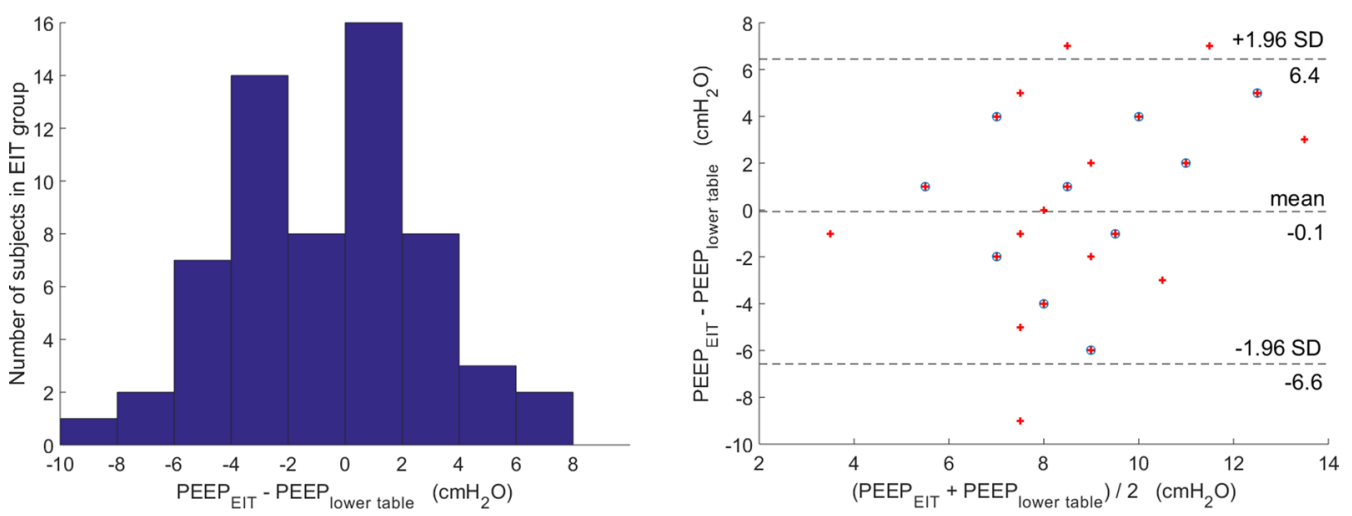

Fig. 3 Distribution of the difference values and agreement of Bland-Altman plot between PEEP ${ }_{\text {eit }}$ and PEEP $P_{\text {lower table }}$ methods in the EIT group. Out of 61 patients, 41 exhibited an absolute difference value between $P E E P_{\text {eit }}$ and $P E E P_{\text {lower table }} \geq 2 \mathrm{cmH}_{2} \mathrm{O}$. Mean difference between the $P E E P$ eit and PEEP lower table was -0.1 [95\% limits of agreement was from 6.4 to $(-6.6) \mathrm{CmH}_{2} \mathrm{O}$ ]

Table 3 Main outcome variables and adjuvant therapies in the two study groups

\begin{tabular}{|c|c|c|c|}
\hline Variables & $\begin{array}{l}\text { EIT group } \\
N=61\end{array}$ & $\begin{array}{l}\text { Control group } \\
N=56\end{array}$ & $p$ value \\
\hline \multicolumn{4}{|l|}{ Clinical outcome } \\
\hline 28-day mortality $(n, \%)$ & $13(21 \%)$ & $15(27 \%)$ & 0.634 \\
\hline $\begin{array}{l}\text { Ventilator-free days at day } \\
28 \text { (D) }\end{array}$ & $14.0(0.0,23.0)$ & $18.5(0.0,24.0)$ & 0.764 \\
\hline Length of ICU stay (D) & $13.0(7.0,25.0)$ & $10.0(7.0,14.8)$ & 0.169 \\
\hline$\triangle \mathrm{D} 1$ SOFA score & $0(-1,1)$ & $0.5(-1,2.75)$ & $0.021^{*}$ \\
\hline$\triangle \mathrm{D} 2$ SOFA score & $-1(-3.5,0)$ & $1(-2,2)$ & $<0.0001^{*}$ \\
\hline $\begin{array}{l}\text { Successful extubation } \\
(n, \%)\end{array}$ & $30(49 \%)$ & $31(55 \%)$ & 0.629 \\
\hline Tracheostomy $(n, \%)$ & $17(28 \%)$ & $11(20 \%)$ & 0.409 \\
\hline \multicolumn{4}{|l|}{ Adjuvant therapy } \\
\hline $\begin{array}{l}\text { Neuromuscular blocker } \\
(n, \%)\end{array}$ & $12(20 \%)$ & $5(9 \%)$ & 0.166 \\
\hline Prone position $(n, \%)$ & $30(49 \%)$ & $23(41 \%)$ & 0.487 \\
\hline $\begin{array}{l}\text { Glucocorticoid therapy } \\
(n, \%)\end{array}$ & $11(18 \%)$ & $6(11 \%)$ & 0.390 \\
\hline
\end{tabular}

$-1(-3.5,0), p=0.001)$. However, the control group did show a similar decrease (difference by $1(-2,2)$, $p=0.131)$.

Based on different severity of $\mathrm{PaO}_{2} / \mathrm{FiO}_{2}$ at baseline, a subgroup analysis of mortality for the mild-moderate and severe ARDS patients was conducted. For the severe ARDS, 5/15 in the EIT versus 2/8 in the control group died $(p=1.00)$. For the mild-moderate ARDS, $8 / 46$ in the EIT versus $13 / 48$ in the control group died $(p=0.26)$.

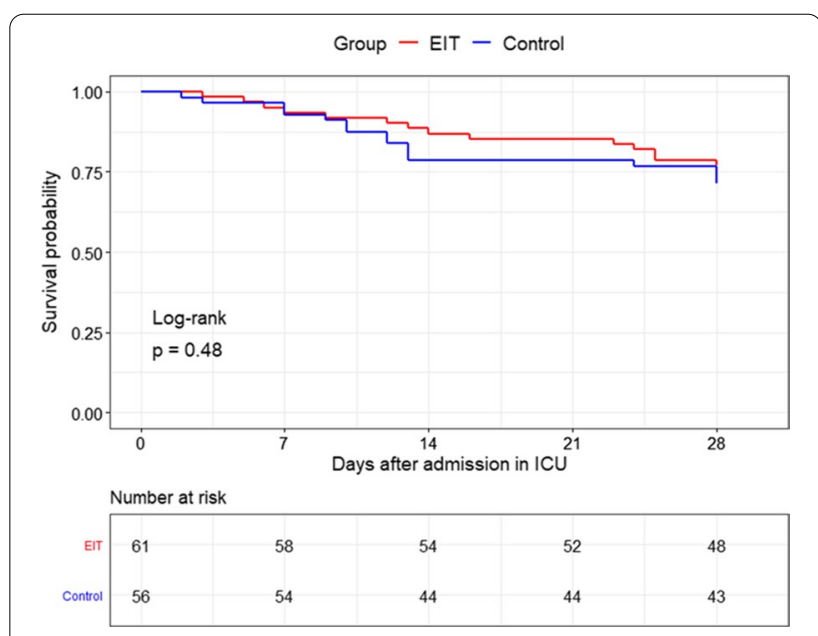

Fig. 4 Kaplan-Meier 28-day probability of survival curve for the EIT group and the control group

\section{Discussion}

In the present study, ARDS patients were randomized and PEEP titration with EIT was compared to low PEEP/ $\mathrm{FiO}_{2}$ table recommended by the ARDS network. We found that early individual PEEP setting with EIT led to a better but insignificant survival rate. Besides, it might also result in a faster early recovery of organ function.

\section{Explanations for lack of survival benefits}

A randomized controlled clinical trial found that PEEP values determined with EIT effectively improved oxygenation and lung mechanics during one lung ventilation in elderly patients undergoing thoracoscopic surgery [10]. One prospective study with historical control group found the EIT-guided PEEP titration 
may be associated with improved oxygenation, compliance, driving pressure, and weaning success rate in severe ARDS patients [11]. Recently, compared with the pressure-volume curve method, Hsu et al. found PEEP titration guided with EIT might be associated with improved driving pressure and survival rate in moderate to severe ARDS [19]. In the present study, we did not find statistical significance between the studied groups. There were several potential reasons for lack of survival benefits in the experimental group. First, the patients we enrolled suffered from mild to severe ARDS. In the first working version of the study protocol before its finalization, we planned to include only moderate to severe ARDS $\left(\mathrm{PaO}_{2} / \mathrm{FiO}_{2}<200 \mathrm{mmHg}\right)$. With the projected limited number of subjects, we decided to extend the study subjects to mild ARDS as well. The mortality rate was much lower than the one we assumed for sample size calculation and the one from Hsu's study [19]. Although the trend might be clinically evident ( $6 \%$ difference) given the higher number of severe ARDS in the EIT group (25\% vs. $14 \%$ ), the low mortality rate limited the power of our study to detect a statistical significance between the groups. Second, the design of the study was to explore early PEEP setting guided by EIT and the differences between groups within a short period. One-day intervention time might be too short to validate the impact of optimal PEEP by EIT on the survival and other endpoints (ICU length of stay, length of mechanical ventilation). Repeated regular use of EIT for individualized PEEP setting in the course of the ICU stay might have led to other outcomes. Third, 20/61 patients obtained an individual PEEP value by EIT which was similar to the PEEP setting method of ARDSnet low PEEP/FiO table. Whether individual PEEP setting by EIT in ARDS can decrease mortality should be assessed in a future larger, possibly multi-center clinical trial.

\section{Strengths of this study}

Reducing morbidity (organ failure) in critically ill patients is intrinsically relevant, and the SOFA score is a valuable endpoint in itself. De Grooth et al. found that $\triangle$ SOFA was significantly associated with mortality and explained $32 \%$ of the treatment effects on mortality [20]. Since a relatively short intervention period (one day) was applied in this study, $\triangle \mathrm{D} 1$ - and $\triangle \mathrm{D} 2$-SOFA might be more reasonable endpoints. The organs failure is common at ARDS onset and during the course of ARDS and is associated with mortality [21-23]. Possible explanations for the improvement of organ function recovery in the EIT group are summarized as follows:
1. Individual parameters (lung collapse and overdistension, inhomogeneities) related to lung injury were taken into consideration in the PEEP setting by EIT. In the EIT group, compared to PEEP setting of ARDSnet table, more than 50\% (41/61) patients exhibited an absolute difference value between PEEP ${ }_{\text {eit }}$ and $\mathrm{PEEP}_{\text {lower table }} \geq 2 \mathrm{cmH}_{2} \mathrm{O}$ in the EIT group. However, PEEP titration according to the ARDSnet table is less individualized. Hochhausen et al. also found that PEEP setting by EIT facilitates a more individual ventilation therapy in an animal study [24].Wolf et al. confirmed that EIT-guided PEEP selection could improve outcomes in the setting of acute lung injury than the PEEP setting of ARDSnet table in an prospective animal study [24, 25]. Moreover, 5/61 (8\%) patients had huge difference $\left(\geq 6 \mathrm{cmH}_{2} \mathrm{O}\right)$ between $\mathrm{PEEP}_{\text {eit }}$ and PEEP $\mathrm{P}_{\text {table }}$ methods in the EIT group. The following two conditions were found: 1 . EIT suggested that a high PEEP causes significant overdistension but little recruitment during the PEEP titration in some patients with a high $\mathrm{FiO}_{2}$. Hence, a low PEEP was determined by PEEP eit , whereas a high PEEP was determined by $P E E P_{\text {table }}$. 2 . EIT suggested that a high PEEP causes a significant regional lung recruitment with little overdistension during the PEEP titration in some patients with a relative low $\mathrm{FiO}_{2}$. Hence, a high PEEP was determined by PEEP ${ }_{\text {eit }}$, whereas a low

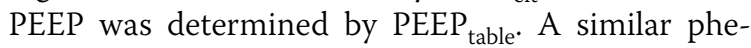
nomenon of huge difference between $\mathrm{PEEP}_{\text {eit }}$ and PEEP $_{\text {table }}$ was also found in the COVID-19 patients [13]. This result supported the PEEP setting by $\mathrm{FiO}_{2}$ might cause a significant lung overdistension or lung collapse in some ARDS patients. Recently, Tsolaki et al. proposed that the PEEP setting based on ARDSnet table might be detrimental in COVID-19 [26].

2. PEEP titration approaches by EIT are based on the assumption that there is an optimal compromise between the limiting the amount of collapse and avoidance of alveolar overdistention. Based on the pathophysiologic theory, the best compromise of regional collapsed and overdistended lung might result in potential benefits regarding circulation and organ functions. Both alveolar collapse and overdistension are harmful during the mechanical ventilation. Moreover, alveolar overdistension exerts a negative effect on the lung circulation and right heart even in the condition of normal oxygenation. Poor right heart function could further impact venous return and then impair the recovery of renal and liver function.

3. No recruitment maneuver was performed before the PEEP trial. A significant improvement in respiratory related parameters (such as oxygenation and respira- 
tory compliance) was not found in the EIT group, and the recovery of organ function might be mainly on the no-respiratory organs. Further studies are required to investigate the effect of PEEP setting by EIT on the individual organs (heart, liver, kidneys, etc.)

\section{Subset analysis based on ARDS severity}

A bigger difference in mortality was observed for the mild-moderate ARDS patients in the subset analysis. The following points should be taken into consideration: 1 . The $\mathrm{PaO}_{2} / \mathrm{FiO}_{2}$ might not be accurate reflecting the severity and prognosis in ARDS patients [27, 28]. DesPrez et al. found that the APACHE II but not $\mathrm{PaO}_{2} /$ $\mathrm{FiO}_{2}$ had the greatest performance to predict mortality in ARDS [27]. 2. Mild-moderate ARDSs usually have shorter treatment period compared to the severe ones, and our protocol only involved different PEEP strategies on the first day. 3 . The statistical power was limit since the subgroup had insufficient sample size. Moreover, there might be a high risk of the selection bias in the small sample of subset analysis.

\section{Limitations}

Further limitations should be acknowledged. 1.The study was not blinded, and the severities of ARDS in the study groups were different. 2. EIT also had the potential to guide PEEP setting in prone position [29,30]. Over the entire hospital stay, more than $40 \%$ of patients received prone positioning. The effect of prone positioning on the results and outcomes was not analyzed in the present study. 3 . The rapidly improving ARDS patients were not excluded in the present study. Twelve of 107 (11.2\%) patients were rapidly improving ARDS in our study, which was similar to the previous RCT of ARDS (about $10-15 \%)$ [31, 32]. Rapidly improving ARDS might negatively affect the prognostic enrichment and contribute to the failure of therapeutic trials [31]. A considerable within-trial variation in the baseline risk of death was found in the RCT of ARDS [33]. Further study is required to validate the PEEP setting by EIT in the ARDS with less heterogeneity. 4. The primary expected outcome of reduced mortality by $25 \%$ was an ambitious target in the initial design of the trial. A recent randomized controlled trial compared PEEP based on EIT and the PV loop in moderate to severe ARDS [19] and reported a $\sim 25 \%$ reduction in mortality. Nevertheless, by setting such a target, the chance was high that the difference between groups was not statistically significant. The expected mortality would be lower than $40 \%$ with a substantial proportion of mild ARDS as in the present study. We acknowledge that the mortality rate of the control group in sample size calculation was only a rough estimation and did not take into account the prevalence of mild ARDS over the years.

\section{Conclusions}

Early individualized PEEP setting by EIT might result in a faster early recovery of organ function. Our study showed a 6\% absolute decrease in mortality in the EIT group: a statistically non-significant, but clinically non-negligible result. This result along with the showed improvement in organ function might justify further reserach to validate the beneficial effect of individualized EIT-guided PEEP setting on clinical outcomes of patients with ARDS.

\section{Key messages}

- Early individualized PEEP setting by EIT might results in a faster early recovery of organ function.

- Whether individualized PEEP setting by EIT in ARDS can decrease mortality should be assessed in a future clinical trial.

\section{Abbreviations}

SOFA: Sequential organ failure assessment; $\mathrm{ScvO}_{2}$ : Central venous oxygen saturation; $\mathrm{PV}_{-} \mathrm{CCO}_{2}$ : Venous-to-arterial carbon dioxide difference; APACHE II: Acute Physiology and Chronic Health Evaluation; ARDS: Acute respiratory distress syndrome; Gl: Global inhomogeneity index; PEEP: Positive end-expiratory pressures; EIT: Electrical impedance tomography.

\section{Acknowledgements}

The authors thank all the subjects for their participation in this study.

\section{Authors' contributions}

$\mathrm{HH}, \mathrm{YYY}, \mathrm{CY}, \mathrm{YL}, \mathrm{SY}$, and $\mathrm{ZZ}$ conceived the study protocol; $\mathrm{HH}, \mathrm{YYY}, \mathrm{CY}, \mathrm{YL}, \mathrm{SY}$, $P Y Z$, and $Z Z$ participated in the design and coordination of the study; $\mathrm{HH}, \mathrm{CY}$, YL, SY, and PZ collected study data; HHW, CY, YL, SY, YYY, PYZ, IF, KM, FF, and ZZ participated in data interpretation; HHW, YYY, CY, YL, SY, and ZZ drafted the present manuscript; HHW, YYY, CY, YL, SY, ZR, PYZ, IF, KM, FF, and ZZ revised the manuscript. All authors read and approved the final version of the manuscript.

\section{Funding}

This work was supported by CAMS Innovation Fund for Medical Sciences (No. CAMS Innovation Fund for Medical Sciences (No. 2020-I2M-C\&T-B-042), Capital's Funds for Health Improvement and Research (No. 2020-2-40111), Excellence Program of Key Clinical Specialty of Beijing in 2020, and Beijing Municipal Science and Technology Commission (Grant No. Z201100005520051). National Natural Science Foundation of China (52077216).

\section{Availability of data and materials}

The datasets used and/or analyzed during the current study are available from the corresponding author on reasonable request. 


\section{Declarations}

\section{Ethics approval and consent to participate}

The ethics review board of Peking Union Medical Collage Hospital approved the study protocol, and written informed consent was obtained from all participants before enrollment.

\section{Consent for publication}

Not applicable.

\section{Competing interests}

Zhanqi Zhao receives a consulting fee from Dräger Medical. Inéz Frerichs reports funding from the European Union's Framework Programme for Research and Innovation Horizon 2020 (WELMO, Grant No. 825572) and reimbursement of speaking fees, congress, and travel costs by Dräger Medical. Other authors declare no conflict of interest.

\section{Author details}

'Department of Critical Care Medicine, State Key Laboratory of Complex Severe and Rare Diseases, Peking Union Medical College Hospital, Peking Union Medical College, Chinese Academy of Medical Sciences, Beijing, China. ${ }^{2}$ Department of Administration, Peking Union Medical College Hospital, Peking Union Medical College, Chinese Academy of Medical Sciences, Beijing, China. ${ }^{3}$ Department of Anesthesiology and Intensive Care Medicine, University Medical Center of Schleswig-Holstein Campus Kiel, Kiel, Germany. ${ }^{4}$ Department of Biomedical Engineering, Fourth Military Medical University, 169 Changle Xi Rd, Xi'an, China. ${ }^{5}$ Institute of Technical Medicine, Furtwangen University, Villingen-Schwenningen, Germany.

\section{Received: 23 April 2021 Accepted: 16 June 2021}

Published online: 30 June 2021

\section{References}

1. Cavalcanti AB, Suzumura EA, Laranjeira LN, Paisani DM, Damiani LP, Guimaraes HP, Romano ER, Regenga MM, Taniguchi LNT, Teixeira C, et al. Effect of lung recruitment and titrated positive end-expiratory pressure (PEEP) vs low PEEP on mortality in patients with acute respiratory distress syndrome: a randomized clinical trial. JAMA. 2017;318(14):1335-45.

2. Zhao Z, Steinmann D, Frerichs I, Guttmann J, Möller K. PEEP titration guided by ventilation homogeneity: a feasibility study using electrical impedance tomography. Crit Care. 2010;14(1):R8.

3. Zhao Z, Möller K, Steinmann D, Frerichs I, Guttmann J. Evaluation of an electrical impedance tomography-based global inhomogeneity index for pulmonary ventilation distribution. Intensive Care Med. 2009;35(11):1900-6

4. Frerichs I, Amato MB, van Kaam AH, Tingay DG, Zhao Z, Grychtol B, Bodenstein M, Gagnon H, Bohm SH, Teschner E, et al. Chest electrical impedance tomography examination, data analysis, terminology, clinical use and recommendations: consensus statement of the TRanslational EIT developmeNt stuDy group. Thorax. 2017;72(1):83-93.

5. Franchineau G, Brechot N, Lebreton G, Hekimian G, Nieszkowska A, Trouillet JL, Leprince P, Chastre J, Luyt CE, Combes A, et al. Bedside contribution of electrical impedance tomography to set positive end-expiratory pressure for ECMO-treated severe ARDS patients. Am J Respir Crit Care Med. 2017:196:447-57.

6. Karsten J, Grusnick C, Paarmann H, Heringlake M, Heinze H. Positive end-expiratory pressure titration at bedside using electrical impedance tomography in post-operative cardiac surgery patients. Acta Anaesthesiol Scand. 2015;59(6):723-32

7. van der Zee P, Somhorst P, Endeman H, Gommers D. Electrical impedance tomography for positive end-expiratory pressure titration in COVID19-related acute respiratory distress syndrome. Am J Respir Crit Care Med. 2020;202(2):280-4.

8. Nestler C, Simon P, Petroff D, Hammermuller S, Kamrath D, Wolf S, Dietrich A, Camilo LM, Beda A, Carvalho AR, et al. Individualized positive endexpiratory pressure in obese patients during general anaesthesia: a randomized controlled clinical trial using electrical impedance tomography. $\mathrm{Br} J$ Anaesth. 2017:119(6):1194-205.
9. Heines SJH, Strauch U, van de Poll MCG, Roekaerts P, Bergmans D. Clinical implementation of electric impedance tomography in the treatment of ARDS: a single centre experience. J Clin Monit Comput. 2019;33(2):291-300.

10. Liu K, Huang C, Xu M, Wu J, Frerichs I, Moeller K, Zhao Z. PEEP guided by electrical impedance tomography during one-lung ventilation in elderly patients undergoing thoracoscopic surgery. Ann Transl Med. 2019;7(23):757

11. Zhao Z, Chang M-Y, Chang M-Y, Gow C-H, Zhang J-H, Hsu Y-L, Frerichs I, Chang H-T, Möller K. Positive end-expiratory pressure titration with electrical impedance tomography and pressure-volume curve in severe acute respiratory distress syndrome. Ann Intensive Care. 2019;9(1):7-7.

12. Fumagalli J, Santiago RRS, Teggia Droghi M, Zhang C, Fintelmann FJ, Troschel FM, Morais CCA, Amato MBP, Kacmarek RM, Berra L. Lung recruitment in obese patients with acute respiratory distress syndrome. Anesthesiology. 2019;130(5):791-803.

13. Sella N, Zarantonello F, Andreatta G, Gagliardi V, Boscolo A, Navalesi P. Positive end-expiratory pressure titration in COVID-19 acute respiratory failure: electrical impedance tomography vs. PEEP/FiO(2) tables. Crit Care. 2020:24(1):540.

14. Brower RG, Lanken PN, Maclntyre N, Matthay MA, Morris A, Ancukiewicz $\mathrm{M}$, Schoenfeld D, Thompson BT. Higher versus lower positive end-expiratory pressures in patients with the acute respiratory distress syndrome. $\mathrm{N}$ Engl J Med. 2004;351(4):327-36.

15. Force ADT, Ranieri VM, Rubenfeld GD, Thompson BT, Ferguson ND, Caldwell E, Fan E, Camporota L, Slutsky AS. Acute respiratory distress syndrome: the Berlin Definition. JAMA. 2012;307(23):2526-33.

16. Costa EL, Borges JB, Melo A, Suarez-Sipmann F, Toufen C Jr, Bohm SH, Amato MBP. Bedside estimation of recruitable alveolar collapse and hyperdistension by electrical impedance tomography. Intensive Care Med. 2009:35(6):1432-1238.

17. Vincent JL, Moreno R, Takala J, Willatts S, De Mendonça A, Bruining H, Reinhart CK, Suter PM, Thijs LG. The SOFA (Sepsis-related Organ Failure Assessment) score to describe organ dysfunction/failure. On behalf of the Working Group on Sepsis-Related Problems of the European Society of Intensive Care Medicine. Intensive Care Med. 1996:22(7):707-10.

18. Roy A. Estimating correlation coefficient between two variables with repeated observations using mixed effects model. Biometrical journal Biometrische Zeitschrift. 2006;48(2):286-301

19. Hsu HJ, Chang HT, Zhao Z, Wang PH, Zhang JH, Chen YS, Frerichs I, Möller $\mathrm{K}$, Fu F, Hsu HS, et al. Positive end-expiratory pressure titration with electrical impedance tomography and pressure-volume curve: a randomized trial in moderate to severe ARDS. Physiol Meas. 2021;42(1):014002.

20. de Grooth HJ, Geenen IL, Girbes AR, Vincent JL, Parienti JJ, Oudemans-van Straaten HM. SOFA and mortality endpoints in randomized controlled trials: a systematic review and meta-regression analysis. Crit Care. 2017;21(1):38.

21. Suchyta MR, Orme JF Jr, Morris AH. The changing face of organ failure in ARDS. Chest. 2003;124(5):1871-9.

22. Dorinsky PM, Gadek JE. Mechanisms of multiple nonpulmonary organ failure in ARDS. Chest. 1989;96(4):885-92.

23. Kallet RH, Lipnick MS, Zhuo H, Pangilinan LP, Gomez A. Characteristics of nonpulmonary organ dysfunction at onset of ARDS based on the Berlin definition. Respir Care. 2019;64(5):493-501.

24. Hochhausen N, Biener I, Rossaint R, Follmann A, Bleilevens C, Braunschweig T, Leonhardt S, Czaplik M. Optimizing PEEP by electrical impedance tomography in a porcine animal model of ARDS. Respir Care. 2017:62(3):340-9.

25. Wolf GK, Gomez-Laberge C, Rettig JS, Vargas SO, Smallwood CD, Prabhu SP, Vitali SH, Zurakowski D, Arnold JH. Mechanical ventilation guided by electrical impedance tomography in experimental acute lung injury. Crit Care Med. 2013:41(5):1296-304.

26. Tsolaki V, Zakynthinos GE, Makris D. The ARDSnet protocol may be detrimental in COVID-19. Crit Care. 2020:24(1):351.

27. DesPrez K, McNeil JB, Wang C, Bastarache JA, Shaver CM, Ware LB. Oxygenation Saturation Index Predicts Clinical Outcomes in ARDS. Chest 2017;152(6):1151-8.

28. Hernu R, Wallet F, Thiollière F, Martin O, Richard JC, Schmitt Z, Wallon G, Delannoy B, Rimmelé T, Démaret C, et al. An attempt to validate the modification of the American-European consensus definition of acute 
lung injury/acute respiratory distress syndrome by the Berlin definition in a university hospital. Intensive Care Med. 2013;39(12):2161-70.

29. Franchineau G, Bréchot N, Hekimian G, Lebreton G, Bourcier S, Demondion P, Le Guennec L, Nieszkowska A, Luyt CE, Combes A, et al. Prone positioning monitored by electrical impedance tomography in patients with severe acute respiratory distress syndrome on veno-venous ECMO. Ann Intensive Care. 2020:10(1):12.

30. Perier F, Tuffet S, Maraffi T, Alcala G, Victor M, Haudebourg AF, De Prost N, Amato M, Carteaux G, Mekontso Dessap A. Effect of positive end-expiratory pressure and proning on ventilation and perfusion in COVID-19 acute respiratory distress syndrome. Am J Respir Crit Care Med. 2020;202(12):1713-7.

31. Schenck EJ, Oromendia C, Torres LK, Berlin DA, Choi AMK, Siempos II. Rapidly improving ARDS in therapeutic randomized controlled trials. Chest. 2019;155(3):474-82.
32. Maley JH, Thompson BT. Embracing the heterogeneity of ARDS. Chest. 2019;155(3):453-5.

33. Santhakumaran S, Gordon A, Prevost AT, O'Kane C, McAuley DF, ShankarHari M. Heterogeneity of treatment effect by baseline risk of mortality in critically ill patients: re-analysis of three recent sepsis and ARDS randomised controlled trials. Crit Care. 2019;23(1):156.

\section{Publisher's Note}

Springer Nature remains neutral with regard to jurisdictional claims in published maps and institutional affiliations.
Ready to submit your research? Choose BMC and benefit from:

- fast, convenient online submission

- thorough peer review by experienced researchers in your field

- rapid publication on acceptance

- support for research data, including large and complex data types

- gold Open Access which fosters wider collaboration and increased citations

- maximum visibility for your research: over $100 \mathrm{M}$ website views per year

At BMC, research is always in progress.

Learn more biomedcentral.com/submissions 